\title{
Evapotranspiration models for a maize agro-ecosystem in irrigated and rainfed conditions
}

\author{
Arianna Facchi, Olfa Gharsallah, Claudio Gandolfi \\ DiSAA, Università degli Studi di Milano, Milano, Italy
}

\begin{abstract}
A high level of accuracy in the estimation of crop evapotranspiration (ET) may lead to significant savings of economic and water resources in irrigated agriculture. Although ET is a fundamental process in many applications, it cannot be directly measured but it has to be estimated by monitoring the exchange of energy/water above the vegetated surface (micrometeorological methods), or as a residual term of the hydrological balance (lysimeters, soil water budget). The techniques to be adopted are often complex, costly and require specific equipment. Thus, since the ' $50 \mathrm{~s}$, many researchers have devoted their activity to the development of models for its estimation. The available approaches can be classified in "direct" methods, based on the original Penman-Monteith (PM) equation, in which the canopy resistance $r_{c}$ is modelled, and "indirect" methods, based on the preliminary calculation of ET for a well-watered reference grass $\left(\mathrm{ET}_{0}\right)$ with a constant $\mathrm{r}_{\mathrm{c}}$, which is then multiplied by a crop coefficient $K_{c}$ and, in case, by a stress coefficient $\mathrm{K}_{\mathrm{s}}$ to obtain ET. Even if the latter approaches are more widely adopted for their practical simplicity, many authors show that the former often provide better ET estimates in absence of calibration of crop parameters. In this study the performances of different direct and indirect methods were evaluated in the case of a surface irrigated and of a rainfed maize grown in the Padana Plain (Northern
\end{abstract}

Correspondence: Arianna Facchi, DiSAA via Celoria 2 , 20133 Milano, Italy. Tel. +39.02.50316909 - Fax: +39.02 .50316911 .

E-mail arianna.facchi@unimi.it

Key words: evapotranspiration, Penman Monteith equation, canopy resistance, Paper FA0-56, crop coefficient, eddy covariance.

Contributions: the authors contributed equally.

Conflict of interests: the authors declare no potential conflict of interests Funding: This research was financed by Regione Lombardia - D.G. Agricoltura.

Acknowledgments: this research was financed by Regione Lombardia - D.G. Agricoltura which is gratefully acknowledged. The authors wish to thank the PoliMi- DIIAR group coordinated by Prof. Marco Mancini with whom the monitoring activity was conducted.

CC Copyright A. Facchi et al., 2013

Licensee PAGEPress, Italy

Journal of Agricultural Engineering 2013; XLIV(s2):e169

doi:10.4081/jae.2013.s2.e169

This article is distributed under the terms of the Creative Commons Attribution Noncommercial License (by-nc 3.0) which permits any noncommercial use, distribution, and reproduction in any medium, provided the original author(s) and source are credited.
Italy). The following models were considered: the "one-layer" original PM equation with three different models for $r_{c}$ (Monteith, Jarvis, Katerji-Perrier), the "two-layers" PM model proposed by Shuttleworth and Wallace, the "single" and "double" crop coefficient models illustrated in the Paper FA0-56. Latent heat fluxes measured in 2006 and 2011 in an experimental maize field by eddy-covariance were used to evaluate the models accuracy. Crop, soil and meteo data monitored contextually were used for the implementation of the different models. Results confirm that direct methods are more performing for both irrigated (2006) and rainfed (2011) conditions, with the SW model providing the best results and the FA0-56 models with generalized crop coefficients overestimating ET, especially during the middle growth stage.

\section{Introduction}

As the water resources available for agriculture become limited due to population growth, competition among different water uses, droughts, and water quality degradation, the importance of quantifying evapotranspiration (ET), which is the major component of water use in agriculture, grows (Farahani et al., 2007). ET cannot be directly measured but it has to be estimated by monitoring the exchange of energy/water above the vegetated surface (micrometeorological methods), or as a residual term of the hydrological balance (lysimeters, soil water budget). The techniques that can be adopted are often complex, costly and require specific equipment, thus they are generally applied only in scientific research.

In most practical situations where crop ET rates are required, the available economic and human resources are not sufficient to allow use of the ET measurement techniques mentioned above, and models are used instead. Since the ' 50 s, many researchers have devoted their activity to the development of models that seek to estimate crop ET from near surface climate data. Early ET models were based on the perception that surface atmosphere exchange was a simple physical phenomenon little influenced by any overlying vegetation cover. This led to empirical relationships between climatic data and the potential rate of evaporation (or evapotranspiration) (e.g., Thornthwaite, 1948; Blaney and Criddle, 1950). In this context, the equation of Penman $(1948,1963)$ was a benchmark. Penman's contribution was to derive a "combination equation" by combining two terms, one of which accounted for the energy required to maintain evaporation ("available energy" term), and the second for the atmosphere's ability to remove water vapour ("aerodynamic" or "sink"term) (Farahani et al., 2007). After that, the modification of Monteith (1965) to the previous equation of Penman moved the axis of the research from a representation of the phenomenon by purely physical laws to one where physiological controls play a fundamental role (Ziemer, 1979). Subsequently, further progress was made in building compartment models based on two or more combination equations, allowing the description of sparse canopies and the partitioning of ET (e.g., Shuttleworth and Wallace, 1985). 
Difficulties in applying combination formulas (particularly related to a lack of consolidated information on the required aerodynamic and surface resistances for different crops and to the need of meteorological data measured above the canopy) led researchers towards an alternative "indirect" approach to estimate the crop evapotranspiration $\left(\mathrm{ET}_{\mathrm{c}}\right)$. This approach is based on a "two-step" procedure: in the first step, the rate of ET was estimated for a reference crop $\left(\mathrm{ET}_{0}\right)$ in wellwatered conditions. This rate was then multiplied by a crop specific coefficient with the objective of estimating $\mathrm{ET}_{\mathrm{c}}$ for different crops. The ratio of $\mathrm{ET}_{\mathrm{c}}$ to the $\mathrm{ET}_{0}$ for a reference crop (short grass or alfalfa), called crop coefficient, $\mathrm{K}_{\mathrm{c}}$ (Jensen, 1968), was then experimentally determined for different growth stages for many crops as the basis for this now long established two step approach for estimating crop water use. The use of $\mathrm{ET}_{0}$ (estimated using local climate data) and associated crop coefficients, $\mathrm{K}_{c}$, became an accepted way to estimate $\mathrm{ET}_{\mathrm{c}}$ for well watered crops, and the $\mathrm{K}_{\mathrm{c}}$ methodology was adopted by the UN's Food and Agriculture Organization (FAO) in the 1970s (Doorenbos and Pruitt, 1977). Its subsequent worldwide promotion was a significant step forward in irrigation engineering and water management (Farahani et al., 2007). Later, in the 1980s and 1990s, there was further rapid progress in data acquisition, remote data access, automation, and in eddy correlation and other measurement techniques. Transfer of technology made available daily values of $\mathrm{ET}_{0}$, facilitating early computer applications for irrigation scheduling (Martin et al., 1990). The superior realism and value of combination equations was recognized, and the PM equation was adopted to estimate $\mathrm{ET}_{0}$ in the $\mathrm{K}_{\mathrm{c}}$ approach (Allen et al., 1994; Allen et al., 1998).

Despite the practical simplicity of using the "indirect" approach is indisputable, many authors in the last fifteen years demonstrated that the adoption of generalized crop coefficient curves can lead to relevant errors in the estimation of ET, since the differences between the $\mathrm{K}_{\mathrm{c}}$ values reported in the FA0-56 Paper (Allen et al., 1998) and the values obtained from locally observed data are up to $\pm 40 \%$, especially during the middle growth cycle (Katerji and Rana 2006). This is mainly due to the complexity of the crop coefficient, which actually integrates several physical and biological factors. On the contrary, many researchers assessed the validity of "direct" approaches (Kato et al., 2004; Farahani and Bausch, 1995; Lafleur and Rouse, 1990), concluding that their ability to simulate the processes is good, provided that the resistances involved are calculated appropriately (Brisson et al., 1998). In order to adopt these models for operational uses, however, the main problems limiting their practical application must be solved.

Both the "direct" and "indirect" methods have their merits and demerits, but certainly very few experiments were conducted applying the different models jointly to the same dataset.

The objective of this study was the investigation of the performance of the most popular "direct" and "indirect" ET methods for a maize agro-ecosystem under well-irrigated and under water-stressed conditions in Northern Italy. In particular, the exercise was conducted using the datasets collected in two agricultural seasons: the first in which the field was irrigated, and the second in which no irrigation event was applied. This allowed to compare the models' performance under different soil water conditions and, at the same time, in conditions ranging from bare to full covered soils. Latent heat fluxes measured by an eddycovariance tower placed in the field were used to test the models performance at the daily time step.

\section{Materials and methods}

\section{The Landriano experimental site}

Data used in this work were collected during the cropping seasons 2006 and 2011 in a 10 ha maize field located in Northern Italy (Landriano), in an experimental farm of the State University of Milan ( $45^{\circ} 19^{\prime}$ N, $9^{\circ} 15^{\prime}$ E, $88 \mathrm{~m}$ a.s.l.). Long-season Zea Mays varieties (FA0 class 600-700) were seeded both years. The crop in 2006 was for silage, seeded after ryegrass and harvested green (emergence: DoY=157, harvesting: DoY=283). In 2011 maize was for forage as well, but it was harvested at the dough stage (maize silage with cobs; emergence DoY=110, harvesting: DoY=244). Maize was chosen for the study since it is the main crop in Northern Italy, covering more than $30 \%$ of the arable land.

Instruments for detailed monitoring of water and energy fluxes were installed in 2005. A micrometeorological eddy covariance (EC) station was located in the centre of the field. Instruments for the monitoring of soil water content and potential were positioned at different depth in a soil profile. Due to the presence of a shallow water table $(90-120 \mathrm{~cm}$ below the topographic surface), a shallow piezometer with a pressure transducer device was also installed. Data were averaged and registered on half an hour basis. Several campaigns were carried out to monitor crop biometric parameters (leaf area index, crop height, rooting depth) and soil properties in both agricultural seasons. Standard meteorological variables were measured on hourly time step by an agro-meteorological station installed in a grass parcel located at $200 \mathrm{~m}$ distance from the experimental field.

The site has a humid subtropical climate according to the Koppen classification system.

During the cropping season 2006 the field was irrigated twice: at DoY $=159$ with the sprinkler method to promote crop emergence, and at DoY=195 with the border method. The water amount applied was estimated to be respectively $25 \mathrm{~mm}$ and $140 \mathrm{~mm}$ in the two events (Baroni et al. 2010). No irrigation was applied in 2011.

Eddy covariance data were post-processed using the TK2 software (Mauder and Foken, 2004). The energy balance closure for daytime $\left(R_{n}>0\right.$ ) 30-min data was equal to $83 \%$ for 2006 and $92 \%$ for 2011 . The gap-filling of missing/eliminated daytime data was conducted determining a regression between half-hourly values of ET and both available energy $\left(R_{n}-G\right)$ and vapour pressure deficit (VPD), only for the days in which at least the $80 \%$ of daytime data were available. Daily ET values were finally calculate summing up the 30 -min data. More information about the experimental site and the processing of eddy covariance data are illustrated in Facchi et al. (2013).

\section{Direct methods}

\section{One-layer Penman-Monteith (PM) model}

The Penman Monteith (1965) "one-layer" model (PM) schematizes the vegetation cover as a single "big leaf" placed at a certain height within the vegetation. The vegetation is taken into account through the canopy and the aerodynamic resistances. The aerodynamic resistance $\left(r_{a}\right)$ is a function of wind and vegetation height. The canopy resistance $\left(\mathrm{r}_{\mathrm{c}}\right)$ is a "bulk" resistance describing the resistance of vapour flow through stomata openings, through the canopy total leaf area and within the soil to the soil surface.

A problem with the PM "one-layer" approach is that areas with partial or sparse vegetation cover don't satisfy completely the hypothesis of "big leaf". The difficulty of providing accurate ET estimates using the PM model in partial canopy conditions $(\mathrm{LAI}<1.5-2)$ has been underlined by several authors (Farahani and Bausch, 1995; Lafleur and 
Rouse, 1990).

In this study, the following three approaches for estimating $r_{c}$ have been selected: a) Monteith, b) Jarvis and c) Katerji and Perrier.

\section{Canopy resistance following Monteith}

For a thick crop canopy it can be assumed that all the leaves behave as resistances in parallel and $r_{c}$ is computed from the ratio between the minimal stomatal resistance $\left(r_{s}\right)$ and the leaf area directly involved in the energy exchange $\left(\mathrm{LAI}_{\mathrm{eff}}\right)$ :

$$
r_{c}=\frac{r_{s}}{L A I_{\text {eff }}}
$$

Several earlier studies fixed the value of the minimal stomatal resistance $r_{s}$ at $100 \mathrm{~s} \mathrm{~m}^{-1}$ for grass type fields (Monteith, 1965; Szeicz and Long, 1969). Subsequently, many authors demonstrated that this variable ranges between 100 and $300 \mathrm{~s} \mathrm{~m}^{-1}$ as a function of the crop type. In this study a value of $252 \mathrm{~s} \mathrm{~m}^{-1}$ was adopted, as suggested by Howell et al. (1997) for maize.

In a fully developed canopy only a fraction of the leaf area index effectively contributes to transpiration, since the photosynthetically active radiation varies through the canopy. A functional relationship between LAI and $\mathrm{LAI}_{\text {eff }}$ suitable for all crops has not yet been found. For a maize crop, Gardiol et al. (2003) reported $\mathrm{LAI}_{\text {eff }}=\mathrm{LAI}$ for $\mathrm{LAI} \leq 2$, $\mathrm{LAI}_{\text {eff }}=0.5 \mathrm{LAI}$ for $\mathrm{LAI} \geq 4$ and $\mathrm{LAI}_{\text {eff }}=2$ for intermediate $\mathrm{LAI}$ values $(2<\mathrm{LAI}<4)$. In this paper an update of this formula is proposed. The PM model with $r_{c}$ by Monteith applies only to well watered soil conditions, since this resistance does not take into account of soil or crop water status.

\section{Canopy resistance following Jarvis}

For more than thirty years, the most widespread approaches to parameterize the effect of environmental factors on stomatal behaviour have been the Jarvis-type models, in which the canopy resistance is expressed as a function of the minimal stomatal resistance $r_{s}$ and a series of independent stress functions $\mathrm{F}_{\mathrm{i}}$ combined in a multiplicative way (each function representing the influence of one factor and providing values ranging from 0 to 1 ). In particular, the Jarvis-type model proposed by Noilhan and Planton (1989) is set as follows:

$r_{c}=\frac{r_{s}}{L A I F_{1} F_{2} F_{3} F_{4}}$

In this study, for consistency with the $\mathrm{r}_{\mathrm{c}}$ modelled following the Monteith approach, LAI=LAI $\mathrm{Lff}_{\text {ff }}$ and $\mathrm{r}_{\mathrm{s}}=252 \mathrm{~s} \mathrm{~m}^{-1}$ (Howell et al., 1997) were adopted. $F_{1}, F_{2}, F_{3}$ and $F_{4}$ represent respectively the influence on $r_{c}$ of photosynthetically active radiation, vapour pressure deficit, air temperature and effective soil water content, and they were modelled as reported in Gharsallah et al. (2013). In particular, the $\mathrm{F}_{4}$ factor was modified with respect to the original version of Noilhan and Planton (1989), becoming:

$$
F_{4}=\left\{\begin{array}{l}
1, \text { if } \theta>\theta_{t} \\
\frac{\theta-\theta_{\text {wilt }}}{\theta_{t}-\theta_{\text {wilt }}} \\
0, \text { if } \theta<\theta_{\text {wilt }}
\end{array} \text {, if } \theta_{\text {wilt }} \leq \theta \leq \theta_{t}\right.
$$

where $\theta$ is the effective soil water content $\left(\mathrm{m}^{3} \mathrm{~m}^{-3}\right), \theta_{\text {wilt }}$ is the soil water content at the wilting point $\left(\mathrm{m}^{3} \mathrm{~m}^{-3}\right)$ while $\theta_{\mathrm{t}}$ is set at the critical soil water content under which the evaporative stress begins following what proposed by Allen et al. (1998). Due to the $\mathrm{F}_{4}$ function, the PM equation with $r_{c}$ following Jarvis is expected to provide good results both under well-watered and water-stressed conditions.

\section{Canopy resistance following the Katerji and Perrier approach}

According to Katerji and Perrier (1983), the latent heat flux is governed by three resistances: the aerodynamic resistance $r_{a}$, the climatic resistance $\mathrm{r}^{*}$, depending only on weather variables, and the canopy resistance $r_{c}$. Through dimensional analysis the authors demonstrated that the resistances $r_{c}$ and $r^{*}$ are linked as follows:

$$
\frac{r_{c}}{r_{a}}=a \frac{r^{*}}{r_{a}}+b
$$

where $\mathrm{a}$ and $\mathrm{b}$ are calibration parameters which vary with the crop type, its phenological stage and its water status, but, according to the authors, they are not site-specific (Rana et al., 1997a). Parameters values for a few crops in different growth stages (active development and senescence) and water conditions (different intervals of leaf water potential) were provided by Rana et al. (1997a, 1997b, 2001). Unfortunately, maize is not among those crops, thus in this study the two parameters were derived from the available data. This is the only calibration operation in the study, performed using some days of the dataset collected at Landriano in 2011. In particular, the dataset was divided into three periods: active development in the absence of crop water stress conditions, active development under crop water stress conditions and senescence. Three representative days for each period were selected, the daytime $\left(R_{n}>0\right) 30$-min canopy resistance $r_{c}$ was determined from the corresponding eddy covariance data by the inversion of the PM equation, a linear regression between the ratio $r_{d} / r_{a}$ and $r^{*} / r_{a}$ was then fitted and the parameters $a$ and $b$ were identified. Obviously, $r_{c}$ from the eddy covariance data, $r^{*}$ and $r_{a}$ were calculated starting from the half-hourly data acquired in the selected days. The a and b values found for the first period of 2011 agricultural season (i.e. active development with absence of water stress) were used for the whole 2006 season, since maize was well-watered and harvested very early that year. Instead, for the agricultural season 2011, a e b values found for the three periods where respectively used. Data used for the a and b calibration were eliminated from the 2011 eddy covariance dataset used for the models' validation. Since the a e b parameter values were identified even under water-stressed conditions, the model is expected to work properly for all soil water status.

\section{Two-layers Shuttleworth (SW) model}

The SW model (Shuttleworth and Wallace, 1985; Shuttleworth and Gurney, 1990) combines two PM type equations for crop transpiration and soil evaporation. Canopy and surface resistances regulate the heat and mass transfer at the plant and soil surfaces and aerodynamic resistances regulate those between the two surfaces and the atmospheric boundary layer. The two terms are computed by the following equations:

$\lambda E T=\lambda T+\lambda E=C_{c} \lambda T 0+C_{s} \lambda E 0$

where $\lambda E T$ is the sum of the latent heat flux from the crop $(\lambda T)$ and the soil $(\lambda \mathrm{E})\left(\mathrm{W} \mathrm{m}^{-2}\right) . \lambda \mathrm{T} 0$ and $\lambda \mathrm{E} 0$ are the terms similar to the PM model and $\mathrm{C}_{\mathrm{c}}$ and $\mathrm{C}_{\mathrm{s}}$ are respectively the canopy resistance and soil surface resistance coefficients.

Different resistances play they role in the model. The soil surface resistance $r_{\mathrm{ss}}$ is interpreted as the resistance for the water vapour to diffuse through the top layer of the soil. Shuttleworth and Wallace (1985) proposed values respectively of 0,500 and $2000 \mathrm{~s} \mathrm{~m}^{-1}$ for $\mathrm{r}_{\mathrm{ss}}$ in various soil water conditions. The canopy resistance $r_{s c}$ was calculated following Eq. 1, while the aerodynamic resistances $r_{a a}$ and $r_{a s}$ as well as the soil surface resistance coefficients $C_{c}$ and $C_{s}$ were computed as reported by Shuttleworth and Gurney (1990) and Kato et al. (2004). The SW model is expected to provide affordable results for bare to full covered soils under water stressed and well-watered conditions. 


\section{Indirect methods}

\section{The FAO-56 "single crop coefficient" model}

In the FA0-56 "single crop coefficient" approach (Allen et al., 1998), crop evapotranspiration $\mathrm{ET}_{\mathrm{c}}$ in optimal water conditions is estimated multiplying the reference evapotranspiration $\mathrm{ET}_{0}$ (calculated applying the PM equation to a "reference grass" having fixed crop parameters) and the crop coefficient $K_{c}$, specific for the crop type and its stage of development. Crop development stages ( $\left.\mathrm{L}_{\mathrm{ini}}, \mathrm{L}_{\mathrm{dev}}, \mathrm{L}_{\mathrm{mid}}, \mathrm{L}_{\text {late }}\right)$ and the corresponding $\mathrm{K}_{\mathrm{c}}$ values $\left(\mathrm{K}_{\mathrm{c} \text { ini }}, \mathrm{K}_{\mathrm{c} \text { mid }}, \mathrm{K}_{\mathrm{c} \text { end }}\right.$ ) are tabulated in the Paper FAO56 for different crops grown in various regions.

For the case study, $\mathrm{K}_{\mathrm{c}}$ curves for years 2006 and 2011 were built considering the length of the crop growth stages observed in the field and adjusting the tabulated crop coefficients with the local data following the procedures indicated by Allen et al (1998). Since maize in 2006 was harvested green and FA0-56 does not provide $K_{c}$ end value for silage maize, $K_{c}$ was kept constant and equal to $K_{c}$ mid till harvesting. Crop stages length and adjusted $K_{c}$ values for 2006 and 2011 are reported in Table 1. More details can be found in Facchi et al. (2013).

To estimate the evapotranspiration in water-stressed condition $\mathrm{ET}_{\mathrm{c}}$ adj, $\mathrm{ET}_{\mathrm{c}}$ must be multiplied by a stress coefficient $\mathrm{K}_{\mathrm{s}}$, which depends on the average soil water content in the root zone as calculated by a daily water balance (Allen et al., 1998).

Since the simple balance model proposed by FA0-56 does not take into account adequately the capillary rise, the "single crop coefficient" approach was applied in this study only for 2006 (for which $\mathrm{ET}_{\mathrm{c} \mathrm{adj}}=\mathrm{ET}_{\mathrm{c}}$ ). As a matter of fact, the capillary rise is very important in soil waterstressed conditions when the water table depth is very shallow, as for the experimental site.

\section{The FAO-56 "double crop coefficient" model}

In the FA0-56 "double crop coefficient" approach (Allen et al., 1998) the separation between the soil evaporation and the crop transpiration fluxes is achieved by splitting the $\mathrm{K}_{\mathrm{c}}$ in two different coefficients: the basal crop $\left(\mathrm{K}_{\mathrm{cb}}\right)$ and the soil evaporation $\left(\mathrm{K}_{\mathrm{e}}\right)$ coefficients, the latter being calculated as a function of the basal crop coefficient and other variables. As for the "single crop coefficient", crop development stages and the corresponding $\mathrm{K}_{\mathrm{cb}}\left(\mathrm{K}_{\mathrm{cb} \text { ini }}, \mathrm{K}_{\mathrm{cb} \text { mid }}, \mathrm{K}_{\mathrm{cb} \text { end }}\right)$ values are tabulated in FA0-56. In the case of soil water stress, $\mathrm{ET}_{\mathrm{c} \text { adj }}$ is calculated from $\mathrm{ET}_{\mathrm{c}}$ considering the two stress coefficients $\mathrm{K}_{\mathrm{s}}$ and $\mathrm{K}_{\mathrm{r}}$ respectively computed from the average water content in the transpirative and in the evaporative zone by daily water balances (Allen et al., 1998).

In this study, $\mathrm{K}_{\mathrm{cb}}$ curves for 2006 and 2011 were built by considering the growing periods length observed in the field and the tabulated $K_{c b}$ values after the adjustments suggested by Allen et al. (1998). The resulting values are reported in Table 1.

The calculation of daily $\mathrm{K}_{\mathrm{r}}$ and $\mathrm{K}_{\mathrm{s}}$ values was carried out with the support of the ALHyMUS model (Gandolfi et al., 2006; Baroni et al., 2010), computing $\mathrm{ET}_{\mathrm{c}}$ on the basis of the "double crop coefficient" proposed by FA0-56. In this model, capillary rise is simulated following Liu et al. (2006).

\section{Time step and performance indicators}

Eddy covariance ET measurements were used to test the models performance for the two datasets at the daily time step. The PM and SW models were applied at the hourly time step, to determine the daily ET amount the sum of hourly daytime outputs $\left(R_{n}>0\right)$ was then carried out. Since the FA0-56 "single" and "double crop coefficient" models were implemented using daily $\mathrm{ET}_{0}$ estimates, they provided directly the daily ET values.

The statistical evaluation of the models' performance was carried out evaluating the linear correlation between observed and measured data (slope of the regression, $\mathrm{M}$, and regression coefficient, $\mathrm{R}^{2}$, were considered) and calculating the root mean square error (RMSE), the mean relative error (MRE) and the Nash-Sutcliffe Efficiency (NSE) indices.

$$
\begin{aligned}
& R M S E=\left[\frac{1}{N} \sum_{i=1}^{N}\left(C_{i}-M_{i}\right)^{2}\right]^{\frac{1}{2}} \\
& M R E=\frac{1}{N} \sum_{i=1}^{N} \frac{\left(C_{i}-M_{i}\right)}{M_{i}} 100 \\
& N S E=1-\frac{\sum_{i=1}^{N}\left(C_{i}-M_{i}\right)^{2}}{\sum_{i=1}^{N}\left(M_{i}-M_{\text {avg }}\right)^{2}}
\end{aligned}
$$

\section{Results and discussion}

\section{Development of a new LAleff function for maize crop}

With the aim of identifying a new and more general equation for $\mathrm{LAI}_{\text {eff }}$ for maize crop, five ET data series measured by the eddy covariance technique were considered. Alongside the data series measured at Landriano in 2006 and 2011, also the one (incomplete) acquired in 2010 at the same site and the two measured in 2010 and 2011 at the Livraga experimental site ( $45^{\circ} 11^{\prime} \mathrm{N}, 9^{\circ} 34^{\prime} \mathrm{E}, 60 \mathrm{~m}$ a.s.l.) were used. For more information about the datasets refer to Facchi et al. (2013). The need to identify a new function emerged because the Gardiol et al. (2003) model, which showed to work well for the 2006 dataset (Gharsallah et al., 2013), led to an unacceptable LAI $\mathrm{eff}_{\text {ef }}$ pattern for 2011, characterized by a fast increase in the $\mathrm{LAI}_{\text {eff }}$ value for $\mathrm{LAI} \geq 4$. As a matter of fact, the maximum LAI value measured in 2006 was around $4 \mathrm{~m}^{2} \mathrm{~m}^{-}$ ${ }^{2}$, while in 2011 this parameter reached a value of about $6 \mathrm{~m}^{2} \mathrm{~m}^{-2}$.

Once daily ET data were obtained for the five eddy covariance datasets, ET values for days characterized by soil water stress conditions were eliminated. Soils were considered in water conditions preventing the occurrence of evapotranspirative stress when the average water content in the rooting depth is higher than $0.15 \mathrm{~m}^{3} \mathrm{~m}^{-3}$ and $0.22 \mathrm{~m}^{3} \mathrm{~m}^{-3}$ respectively for the Landriano and Livraga sites (Facchi et al., 2013).

Crop resistance $r_{c}$ was obtained for each day by inverting the PM equation following the Monteith approach for $r_{c}$. The obtained $r_{c}$, as well as the measured LAI values, were then plotted in function of the cumulative ground degrees days (GDD) starting from the seeding date

Table 1. Crop stages length observed in the field and $K_{c}$ and $K_{c b}$ adjusted considering local data.

\begin{tabular}{lcc} 
Parameter & 2006 & 2011 \\
$\mathrm{~L}_{\text {ini }}$ & 25 & 29 \\
$\mathrm{~L}_{\text {dev }}$ & 26 & 40 \\
\hline $\mathrm{L}_{\text {mid }}$ & 56 & 51 \\
$\mathrm{~L}_{\text {late }}$ & 27 & 26 \\
\hline $\mathrm{K}_{\mathrm{c} \text { ini }}$ & 0.29 & 0.28 \\
$\mathrm{~K}_{\mathrm{cmid}}$ & 1.16 & 1.14 \\
\hline $\mathrm{K}_{\mathrm{c} \text { end }}$ & $1.16^{*}$ & 0.57 \\
$\mathrm{~K}_{\mathrm{cb} \text { ini }}$ & 0.15 & 0.15 \\
\hline $\mathrm{K}_{\mathrm{cb} \text { mid }}$ & 1.11 & 1.09 \\
$\mathrm{~K}_{\mathrm{cb} \text { end }}$ & $1.11^{*}$ & 0.52 \\
\hline${ }^{\text {crop was harvested green }}$ & &
\end{tabular}


(Facchi et al., 2013). The use of GDD instead of the number of days reduces the data dispersion due to the different climatic conditions, and allows to consider data of a second crop maize (Landriano 2006) together with those of a first crop maize. The obtained data are shown in Figure 1.

Two approaches for the estimation of $\mathrm{LAI}_{\text {eff }}$ are proposed. The first one can be applied when measured LAI values are available. In that case, the Gardiol et al. (2003) model is modified as follows: $\mathrm{LAI}_{\mathrm{eff}}=\mathrm{LAI}$ for $L A I \leq 2, L_{A I}$ eff $=2$ until the end of the middle season stage, $\mathrm{LAI}_{\mathrm{eff}}$ linearly decreasing from 2 to 0.3 in the case of a complete senescence, to 0.35 for a dough stage harvesting, to 0.5 for silage maize.

The second approach can be adopted when measured LAI data are not available: $\mathrm{LAI}_{\text {eff }}=0.2$ for initial stage $\left(\mathrm{L}_{\mathrm{ini}}\right), \mathrm{LAI}_{\text {eff }}$ between 0.2 and 2 for the crop development stage $\left(\mathrm{L}_{\mathrm{dev}}\right), \mathrm{LAI}_{\mathrm{eff}}=2$ for the middle season stage $\left(\mathrm{L}_{\mathrm{mid}}\right)$, and $\mathrm{LAI}_{\text {eff }}$ as in the first approach for the late season stage (Llate).

\section{Comparsion of ET models under well-watered conditions (2006)}

Results of the models application and performance indices are reported in Figure 2 and Table 2.

All the "direct" approaches for ET estimation provide a very good agreement with the observations during the entire agricultural season. In particular, as expected given the lack of soil water stress conditions, the result provided by the model of PM with $r_{c}$ by Jarvis is very close to that obtained with $r_{c}$ by Monteith. Slightly lower performances are provided by the PM model with $r_{c}$ by KP, even if the result is very satisfactory considering that the parameters a and $b$ were calibrated using an independent data set (i.e. 2011). The SW model shows the best performance, behaving well also for days with sparse canopy and peak evaporation rate following irrigation and rainfall events. ET values estimated with the "single" and "double crop coefficient" approaches are higher than the observed, probably because of the excessively high values of $K_{c}$ and $K_{c b}$ obtained following the methodology FA0-56 when compared with those obtained from experimental observations in Northern Italy (Facchi et al., 2013).

\section{Comparsion of ET models under water-stressed conditions (2011)}

Figure 3 and Table 3 show the performances of ET models under water-stress conditions, which basically confirm the results obtained

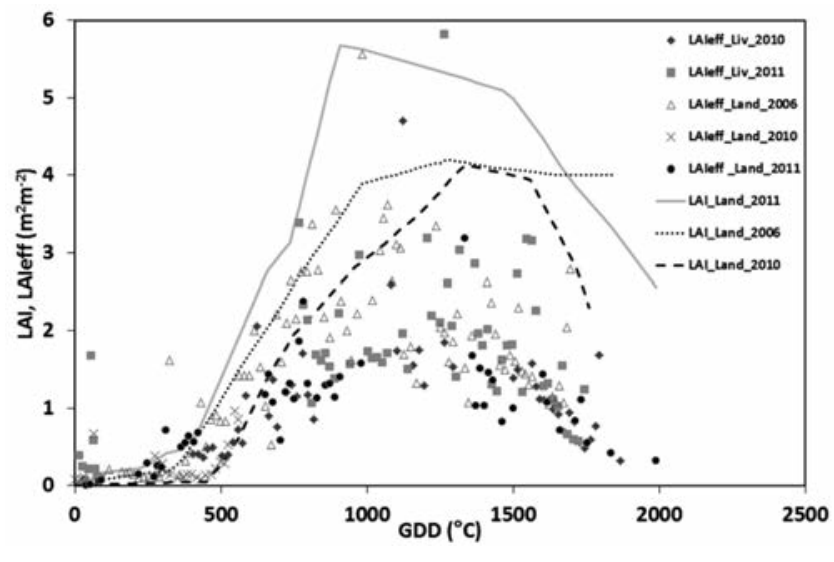

Figure 1. LAIeff derived from field measurements, measured LAI and average $\mathrm{LAI}_{\text {eff }}$.
Table 2. Performance indices calculated for the ET models at Landriano in 2006.

\begin{tabular}{lccccc} 
ET models & M & R2 & RMSE & MRE & NSE \\
PM (rc Monteith) & 0.98 & 0.86 & 0.52 & -1.25 & 0.87 \\
PM (rc Jarvis) & 0.96 & 0.86 & 0.53 & -3.20 & 0.86 \\
\hline PM (rc KP) & 1 & 0.73 & 0.69 & 9.56 & 0.76 \\
SW & 1.05 & 0.93 & 0.42 & 7.43 & 0.91 \\
\hline FA0-56 "single crop" & 1.12 & 0.82 & 0.79 & 16.8 & 0.68 \\
FA0-56 "double crop" & 1.24 & 0.82 & 1.17 & 23.53 & 0.31 \\
\hline
\end{tabular}
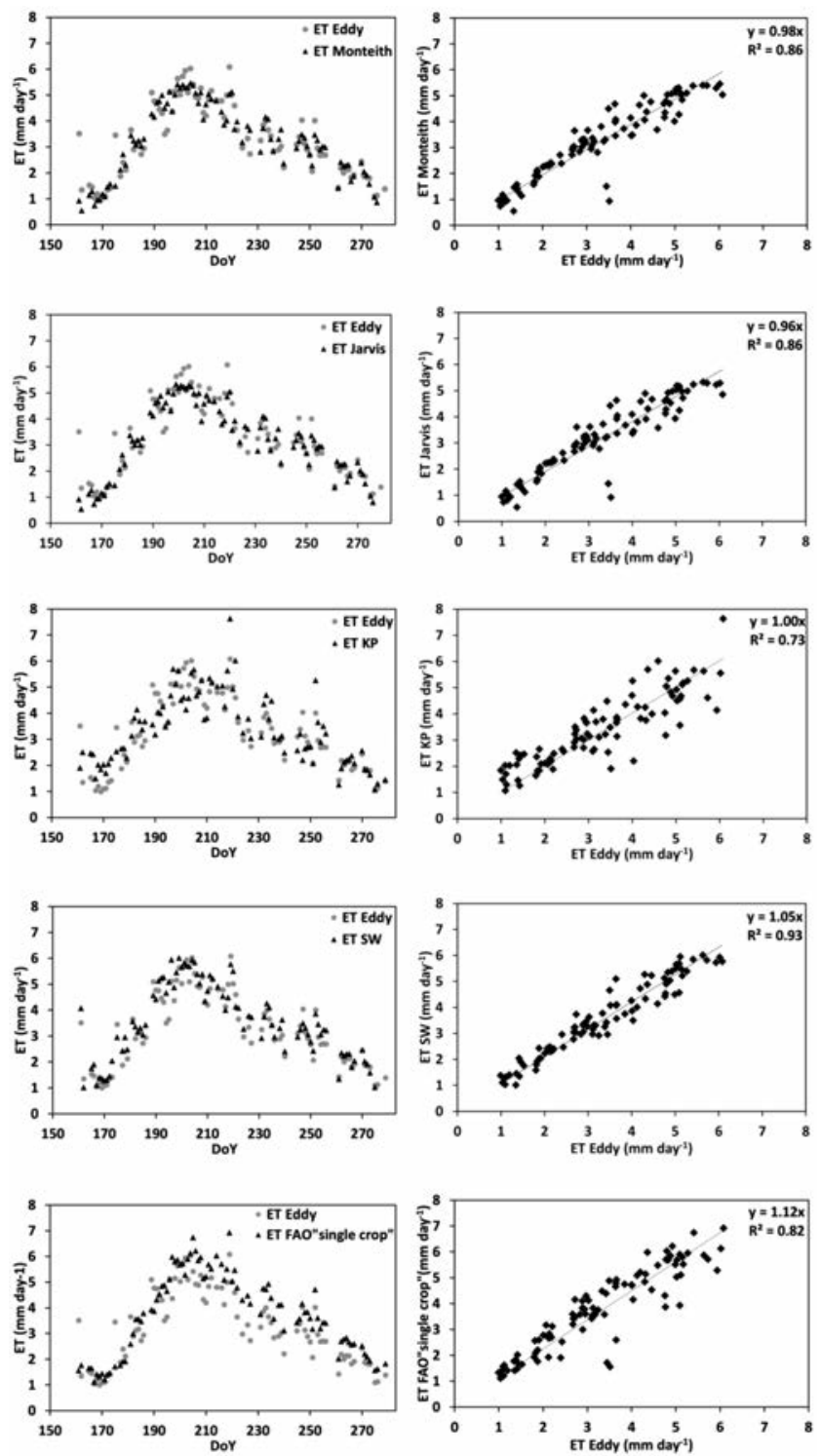

Figure 2. On the left: daily ET estimated by the different ET models and measured by the eddy covariance technique at Landriano in 2006. On the right: correlation between the measured and estimated data series. 
Table 3. Performance indices calculated for the ET models at Landriano in 2011.

\begin{tabular}{lccccc} 
ET models & $\mathrm{M}$ & $\mathrm{R}^{2}$ & RMSE & MRE & NSE \\
PM ( $\mathrm{r}_{\mathrm{c}}$ Jarvis $)$ & 0.97 & 0.56 & 0.65 & 2.75 & 0.72 \\
PM $\left(\mathrm{r}_{\mathrm{c}} \mathrm{KP}\right)$ & 1.01 & 0.74 & 0.51 & 7.89 & 0.78 \\
\hline SW ( $\mathrm{r}_{\mathrm{c}}$ Jarvis $)$ & 0.99 & 0.67 & 0.56 & 6.78 & 0.73 \\
FAO-56_adj“double crop" & 1.16 & 0.68 & 1.05 & 267.43 & 0.04 \\
\hline
\end{tabular}
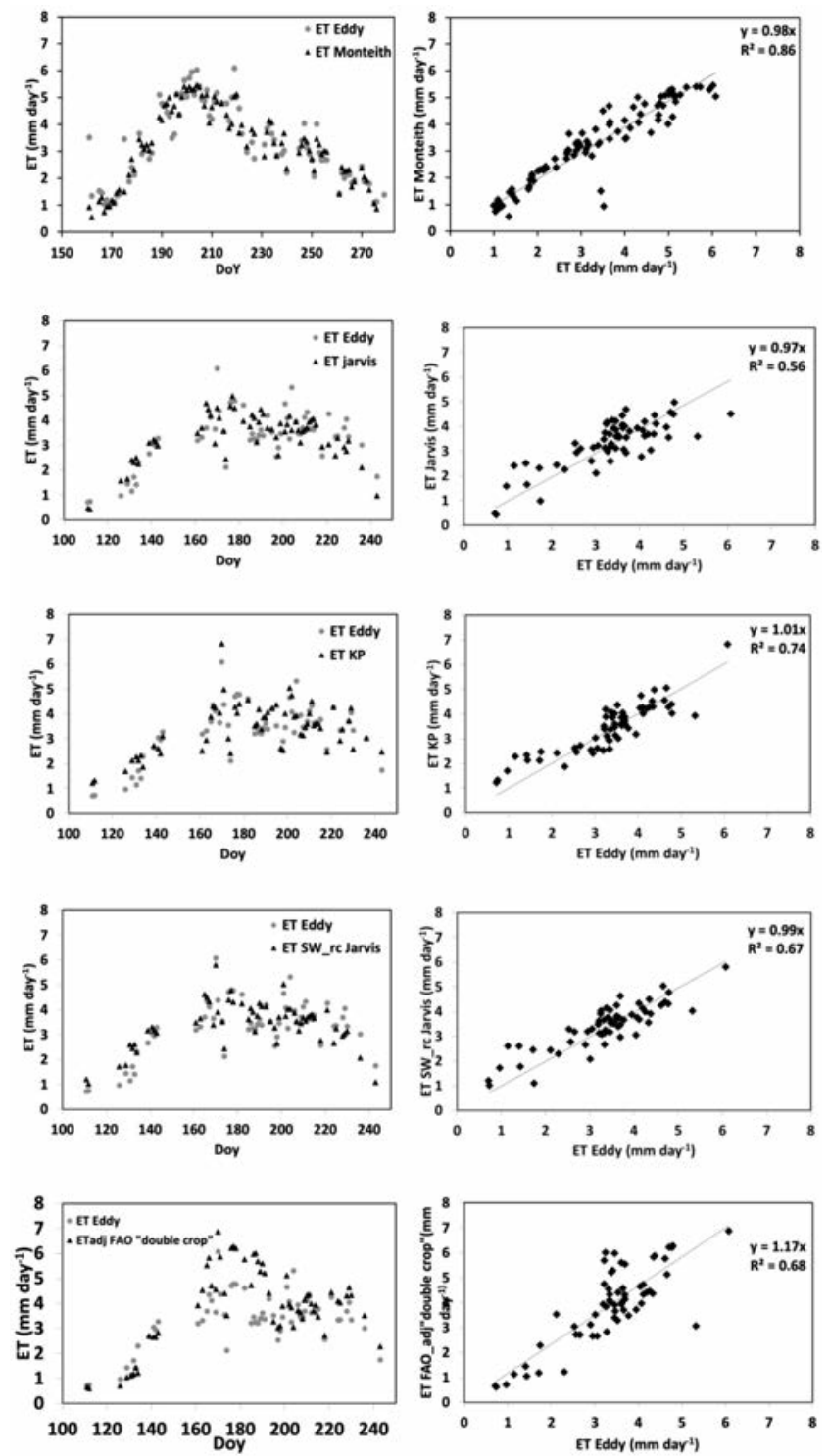

Figure 3. On the left: daily ET estimated by the different ET models and measured by the eddy covariance technique at Landriano in 2011. On the right: correlation between the measured and estimated data series. under well-watered conditions, with the "direct" approaches giving the best results. It can be noted that the PM equation with $r_{c}$ modelled following KP gives the best results, outperforming the PM with $r_{c}$ by Jarvis, probably because the parameters a and b were calibrate using data of the 2011 dataset. Anyway, the performances for the three "direct" methods are comparable. As in the well-watered case, the performance of the FA0-56 model is the poorest.

A comparison between indices in Table 2 and Table 1 shows that in water-stressed conditions, even if the index values indicate good performances for all the "direct" models, these are slightly lower than those found for the well-watered case. In particular, the dispersion around the regression line increases, especially - but not only - at lower ET values (with a decreasing of $\mathrm{R}^{2}$ ), and the NSE values are higher. This can be explained by the fact that in water-stressed condition ET deviates from its potential value, becoming more difficult to estimate, since it starts to depend from a higher number of factors.

\section{Conclusions}

The main findings of this study are: i) in absence of calibration of the crop parameters, direct methods provide better performances than the indirect methods, confirming the findings of several authors in the literature; ii) the use of a new and simple function for estimating $\mathrm{LAI}_{\text {eff }}$ for a maize crop in the different growth stages, proposed in this study, improves the performances of direct models at high values of LAI, compared to the most widely used functions reported in the literature; iii) the SW model is a robust model providing very good performance for the entire agricultural season under different soil water status conditions, but it requires complex procedures to estimate the various resistances involved; iv) the one-layer PM equation also provides good results in well-watered and water-stressed conditions with $r_{c}$ by Jarvis and KP; v) the "single" and "double crop coefficient" FA0-56 models overestimate ET for the entire agriculture season; this is due to the fact that the crop coefficients, even if adjusted with local data, are overestimated, pointing to the necessity of determining site-specific crop coefficients ; vi) the main obstacle to the routine use of direct approaches, such as both PM and SW models, is the need of micrometeorological measurements taken above the crop (e.g., $\mathrm{R}_{\mathrm{n}}, \mathrm{VPD}$, wind speed) and the lack of consolidated information on surface resistances for the different crops, which call for further research to make these methods more applicable operatively.

\section{References}

Allen R. G., M. Smith., Perrier L., Pereira L. S. 1994. An update for the definition of reference evapotranspiration. ICID Bull. 43 A. (2): 134.

Allen R.G., Pereira L.S., Raes D., Smith M. 1998. Crop evapotranspiration (guidelines for computing crop water requirements). Irrigation and Drainage Paper 56. FAO. Food and Agriculture Organization of the United Nations. Rome, Italy.

Baroni G., Facchi A., Gandolfi C., Ortuani B., Horeschi D., Van Dam J.C. 2010. Uncertainty in the determination of soil hydraulic parameters and its influence on the performance of two hydrological models of different complexity. Hydrol. Earth. Syst. Sci (HESS). 6: 40654105.

Blaney H. F., Criddle W. D. 1950. Determining water requirements in irrigated areas from climatological and irrigation data. TP-96. Washington, D.C.: USDA Soil Conservation service. 
Brisson N., Itier B., L'Hotel J.C., Lorendeau J.Y. 1998. Parameterisation of the Shuttleworth-Wallace model to estimate daily maximum transpiration for use in crop models. Ecol. Model. 107 (2-3): 159169.

Doorenbos J., Pruitt W.0. 1977. Crop water requirements. Irrigation and Drainage Paper FAO 24. Food and Agriculture Organization of the United Nations. Rome, Italy, Rome, Italy

Facchi A., Gharsallah 0., Gandolfi C., Corbari C., Mancini M. 2013. Eddy covariance for the determination of crop coefficients and crop water requirements for maize in Northern Italy. Accepted by Agric. Water Manage.

Farahani H.J., Bausch W.C. 1995. Performance of evapotranspiration models for maize: Bare soil to closed canopy. Trans. ASAE. 38: 1049-1059.

Farahani H. J., Howell T. A., Shuttleworth W. J., Bausch W. C. 2007. Evapotranspiration: progress in measurement and modelling in agriculture. Transactions of the ASABE. 50(5):1627-1638.

Gandolfi C., Facchi A., Maggi D. 2006. Comparison of 1D Models of Water Flow in Unsaturated Soils. Environ. Model. Soft. 21: 17591764.

Gharsallah 0., Facchi A., Gandolfi C., 2013. Comparison of six evapotranspiration models for a surface irrigated maize agro-ecosystem in Northern Italy. Accepted by Agric. Water Manage.

Gardiol J.M., Serio L.A., Maggiora A.I.D. 2003. Modelling evapotranspiration of corn (Zea mays) under different plant densities. J. Hydrol $.217,188-196$.

Howell T.A., Steiner J.L., Schneider A.D., Evett S.R., Tolk J.A. 1997. Seasonal and maximum daily evapotranspiration of irrigated winter wheat, sorghum, and corn-Southern High Plains. Trans. ASAE. 40(3): 623-634.

Jarvis, P.G., 1976. The interpretation of the variation in leaf water potential and stomatal conductance found in canopies in the field. Philos. Trans. Roy. Soc. London, Ser B. 273: 593-610.

Jensen M. E. 1968. Water consumption by agricultural plants. In Water Deficits and Plant Growth, 1-22. T. T. Kozlowski, ed. New York, N.Y.: Academic Press.

Kato T., Kimura R., Kamichika M. 2004. Estimation of evapotranspiration, transpiration ratio and water-use efficiency from a sparse canopy using a compartment model. Agric. Water Manage. 65 :173191.

Katerji N., Perrier A. 1983. Modélisation de l'évapotranspiration réelle d'une parcelle de luzerne : rôle d'un coefficient cultural. Agron. J. 3(6): 513-521.

Katerji N., Rana G., 2006. Modelling evapotranspiration of six irrigated crops under Mediterranean climate conditions. Agric For Meteorol.
138: $142-155$.

Lafleur P.M., Rouse W.R. 1990. Application of an energy combination model for evaporation from sparse canopies. Agric For Meteorol. 49(2) : 135-153.

Liu Y., Pereira L. S., Fernando R.M. 2006. Fluxes through the bottom boundary of the root zone in silty soils: parametric approaches to estimate groundwater contribution and percolation. Agric. Water Manag. 84: 27-40.

Mauder M., Foken T. 2004. Documentation and Instruction Manual of the Eddy Covariance Software Package TK2. University Bayreuth, Abt. Micrometeorologies, Germany.

Martin D. L., Heermann D. F., Fereres E. 1990. Irrigation scheduling principles. In Management of Farm Irrigation Systems: 155-203.

Monteith J.L. 1965. Evaporation and environment. In: Fogg, B.D. (Ed.) The State and Movement of Water in Living Organism. Symp. Soc. Exp. Biol. 19: 205-234.

Noilhan J., Planton S. 1989. A Simple Parameterisation of Land and Surface Process for Meteorological Models. American. Meteorol. Soc. 117: 536-549.

Penman H.L. 1948. Natural evaporation from open water, bare soil and grass. Proc. Roy. Soc. Ser A. 193: 120-146.

Penman H. L. 1963. Vegetation and hydrology. Tech. Comm. No. 53. Harpenden, U.K.: Commonwealth Bureau of Soils. Expression et paramètres donnant l'évapotranspiration réelle d'une surface mince. Ann. Agron .26 : 105-123.

Rana G., Katerji N., Mastrorilli M., El Moujabber M. 1997a. A model for predicting actual evapotranspiration under water stress conditions in a Mediterranean region. Theor. Appl. Climatol. 56: 45-55.

Rana G., Katerji N., Mastrorilli M., El Moujabber M. 1997b. Canopy resistance modelling for crops in contrasting water conditions. Phys. Chem. Earth. 23(4): 433-438.

Rana G., Katerji N., Perniola M. 2001. Evapotranspiration of sweet sorghum: a general model and multilocal validity in semiarid environmental conditions. Water. Resour. Res. 37(12): 3237-3246.

Shuttleworth W.J., Wallace J.S. 1985. Evaporation from sparse crops-an energy combination theory. Q. J. R. Meteorol. Soc. 111: 839-855.

Shuttleworth W.J., Gurney R.J., 1990. The theoretical relationship between foliage temperature and canopy resistance in sparse crops. Q. J. R. Meteorol. Soc. 116: 497-519.

Szeicz G., Long I.F. 1969. Surface resistance of crop canopies. Water. Resour. Res. 5: 622-633.

Thornthwaite C. W. 1948. An approach toward a rational classification of climate. Geography Rev. 38(1): 55-94.

Ziemer R.R. 1979. Evaporation and transpiration. Reviews of geophysics and space physics. 17(6): 1175-1186. 